\title{
Mastering the Digital Transformation Process: Business Practices and Lessons Learned
}

\author{
Lucija Ivančić, Vesna Bosilj Vukšić, and Mario Spremić
}

\author{
"The consumer society is so all-pervasive today that it is" \\ easy to assume it has always existed. Yet, in reality, it is \\ one of the more recent innovations that propelled the \\ West ahead of the Rest.
}

\author{
Niall Ferguson \\ Economic historian, professor, and author \\ In Civilization: The West and the Rest
}

\begin{abstract}
Due to its unique features and accessibility, the focus of implementing digital technology is no longer just to improve internal operations, but to expand internal dimensions, reach customers and external partners, affect services, integrate processes, disrupt markets, and fundamentally change industries. It is no surprise that the notion of digital transformation has garnered much research interest, especially from the practitioners' point of view, but academic achievements are somehow lagging behind, possibly because frameworks for digital transformation are still evolving. In this article, we tried to address that gap by conducting holistic research of digital transformation in companies. We used a series of in-depth interviews to inform comprehensive case studies of three companies from different industries that are in different stages of digital transformation. We carefully investigated the companies' experiences in the process of digital transformation, which are discussed here to provide valid theoretical framing. We conclude that, in addition to technology adoption, important factors for successful digital transformation are the ability of an organization to change and operational excellence in the integration of external digital services with internal IT support. In that light, we summarize our findings in a form of discovered (sub)dimensions that are the basis for the proposed digital transformation framing, while the narratives and case experiences provide with examples of best practice.
\end{abstract}

\section{Introduction}

Digital transformation can be comprehended as a continuous process of climbing the scale of digital maturity by employing digital and other technologies along with organizational practices to create a digital culture. Ultimately, this maturity will enable the company to provide better services, gain competitive advantage, and effectively respond to actions in a complex environment. Companies that successfully employ digital transformation enjoy better returns on their assets and are generally more profitable (Westerman et al., 2012).

In response to the promise of these positive business outcomes, digital transformation and digitization have become common "buzzwords" in both the business world and the academic community. Studies on digit- al transformation date back as far as a dozen years ago (Kohli \& Johnson, 2011; Zhu et al., 2006), but have only recently aroused greater scientific interest (Bosilj Vukšić et al., 2018). Digital transformation has been mostly investigated by prominent research centres in collaboration with professional experts from consulting companies (e.g., Gill \& Van Boskirk, 2016; Kane et al., 2015; Westerman et al., 2011), whereas academic researchers are somewhat lagging behind. From the practitioners' point of view, there is a struggle in finding effective ways of conducting digital transformation (Lucas et al., 2013; World Economic Forum, 2018). Moreover, academic achievements offer little help given that digital transformation is an emerging field and the body of literature still provides limited value in terms of representative case study examples that practitioners can actually benefit from (Bosilj Vukšić et al., 2018; Henriette et al., 2015). 


\section{Mastering the Digital Transformation Process: Business Practices and Lessons Learned Lucija Ivančić, Vesna Bosilj Vukšić, and Mario Spremić}

Hence, there are opportunities for further scientific research that will yield both practical implications and better scholarly understanding of digital transformation. Our research aims to contribute to the field of digital transformation topic addressing the identified research gap. Therefore, in order to shed some light on the digital transformation concept, our study aims to achieve the following research objectives:

1. To conduct a holistic and comprehensive investigation of all aspects of digital transformation.

2. To propose empirically grounded directions for developing a framework for digital transformation and its business implementation.

This article is structured as follows. After the introduction, we briefly describe our methodology. Next, we present our findings by systematically describing our case companies' experiences in the digital transformation process, and we present the digital transformation sub-dimensions we identified through the analysis. The discussion that follows emphasizes recommendations and lessons that can be learned from the experience of the studied companies. Finally, we offer concluding remarks and identify future research directions.

\section{Methodology}

We adopted a qualitative approach by conducting three case studies to address the research objectives. Qualitative reasoning has been extensively used in information systems research since, according to Myers (1997), a shift of interest has been made in direction of organizational issues of information systems science. Consequently, a case study approach gives good justifications for questions of "what" (descriptive design), or "how" or "why" (explorative design) a certain phenomenon occurs, and for obtaining first-hand and in-depth understanding (Yin, 2006). In addition, case study investigations are considered appropriate when a topic needs to be explained in detail or in relation to the context, as well as for early research stages of defining the variables of research topic by employing a holistic vision (Benbasat et al., 1987; Matthews \& Ross, 2010; Myers, 1997). Therefore, a case study design was chosen for fulfilling the objectives of this study given that its aim is to gain first-hand insights and clarify digital transformation practices in companies in a holistic manner. The adopted case study approach is well established and accepted in different information systems areas and in the related literature in general (Niehaves et al., 2014), including digital transformation (Kohli \& Johnson, 2011; Sebastian et al., 2017), since it allows researchers to study practices and situations that are understudied and not yet completely described and comprehended, such as the topic of digital transformation.

Prior to conducting the case studies in companies, a case study protocol was made, including research objectives, data collection methods, and interview protocol with questions and prompts to ensure reliability. We followed the work of Kane and coauthors (Kane et al., 2016) and adapted it to match our research objectives, alongside the experience and knowledge of the authors related to organizational science, business process management, IT, and digital transformation, in order to convey a set of guiding questions utilized in semi-structured interviews (Appendix 1) with top-level managers. Interviews are typical source of data in case research (Myers \& Newman, 2007; Sebastian et al., 2017; Vukšić et al., 2013) and were chosen as a data collection method because we wanted to obtain opinions and experiences of top-level managers on the digital transformation processes, efforts, and utilized practices in their companies. We decided not to use a completely free-form interview format because, although qualitative in nature, we wanted the results to be somewhat comparable in order to deliver more relevant results in a cross-sectional study. Hence, we opted for semi-structured interviews. The questionnaire tool option was discarded because our interest was not in the strict form and quantification of digital transformation in the case companies but, rather, we sought business practices and lessons learned in the process of digital transformation. According to Matthews and Ross (2010), semistructured interviews are appropriate for this research objective because they enable free expression by interviewees and they yield more and specific information on the topic and explanation of occurring behaviours and practices.

We conducted three interviews in total with four Clevel executives in charge of digital transformation in their companies. Each interview lasted for about an hour and was recorded with the informant's permission. A few interviews lacking information identified as relevant for subsequent analysis were supplemented with details acquired from the interviewees at a later date. We followed coding and analysis case study protocol outlined by Voss, Tsikriktsis, and Frohlich (2002) who suggest taking a three-step approach for case study data coding and analysis: data fragmentation 


\section{Mastering the Digital Transformation Process: Business Practices and Lessons Learned Lucija Ivančić, Vesna Bosilj Vukšić, and Mario Spremić}

(open coding); cross-case analysis; rearranging data for new insights (axial coding). First, the interviews were transcribed. The transcripts were afterwards used to summarize the findings in a coding procedure using Microsoft Word and Excel. A procedure for data analysis included coding of general information found in transcripts by marking the focal parts and important information of the interview. After that, a dimension notation that most precisely describes these parts was added in the transcript. In the end, a cross-case analysis was conducted in order to extract general dimensions from the text alongside with somewhat richer explanations that were used to identify sub-dimensions. This type of coding and data analysis protocol is common for studies using interviews as a data gathering method (e.g., Buh et al., 2015; Sebastian et al., 2017). On top of that, narratives and case-specific information were used to depict organizational practices and lessons learned from our case companies.

\section{Case Selection}

This research was conducted in three companies operating in Croatia, but which have strong ties to other markets. In addition, all of the companies had been in the market long enough to experience necessary changes from old ways of doing work to the modern requirements of the digital age, which makes them appropriate for research on digital transformation. Additionally, the country context is a relatively small European economy where awareness of the importance of digital transformation among established companies is not completely developed. Case selection therefore focused on companies that: i) have started digital transformation projects; ii) are advocates of digital transformation in the business community; and iii) have ties to other markets.

An overview of the three selected case companies is provided in Table 1. For privacy reasons, alias names for these companies have been used in the article. Case company A is a telecommunications provider, here named Teleop, with a parent company in Western Europe that has branches in more than 50 countries and has more than 200,000 employees. Case B, here named Manufact, operates in the manufacturing sector. It has export-oriented production and is a global market player in its niche. Case C company, here named Insurer, is a regional leader in the insurance industry that has branches in 6 regional countries and has more than 2,000 employees in Croatia only.

\section{Findings}

In our analysis, distinctive orientations taken in digital transformation directions can be observed among the three case companies, especially when viewed in light of their different industries. Manufact's digital transformation efforts are focused on gaining competitive advantage through production speed, Insurer appraises operational excellence, while Teleop focuses on building digital services infrastructure developed in cooperation with partners. Nonetheless, of the sector-specific differences, general conclusions about the setup of digital transformation can be drawn. The multiple case

Table 1. Overview of the three case companies

\begin{tabular}{|c|c|c|c|}
\hline & $\begin{array}{l}\text { Case A } \\
\text { Teleop }\end{array}$ & $\begin{array}{c}\text { Case B } \\
\text { Manufact }\end{array}$ & $\begin{array}{c}\text { Case C } \\
\text { Insurer }\end{array}$ \\
\hline Industry & Telecommunications & Heavy manufacturing & Insurance \\
\hline Number of employees & 3,550 & 315 & 2,100 \\
\hline Average revenues in the last three years & $€ 820$ million & $€ 30$ million & $€ 345$ million \\
\hline Year of foundation & 1998 & 1976 & 1964 \\
\hline Started digital transformation & 6 years ago & 1 year ago & 2 years ago \\
\hline Formal role of Chief Digital Officer (CDO)? & Yes & No & Yes \\
\hline Part of an international subsidiary? & Yes & No & Yes \\
\hline Head of subsidiaries? & No & $\mathrm{N} / \mathrm{A}$ & Yes \\
\hline
\end{tabular}




\section{Mastering the Digital Transformation Process: Business Practices and Lessons Learned Lucija Ivančić, Vesna Bosilj Vukšić, and Mario Spremić}

study approach has enabled us to identify seven dimensions of digital transformation - strategy, people, organization, customer, ecosystem, technology, and innovation - and their corresponding sub-dimensions, as summarized in Table 2.

As shown in Table 2, most of the sub-dimensions apply to more than one case, if not all three. However, due to specific requirements of work arrangements and business in diverse sectors, our in-depth content analysis of the interview transcripts revealed certain company-specific features that are described in the forthcoming narratives and are more detailed explanations of findings presented in Table 2. In addition, narratives depicture miscellaneous practices employed by companies to foster digital transformation and accompanying organizational changes that can serve as good practice examples. Also, case practices in the following sub-sections are discussed in relation to and corroborated by findings from other existing studies on specific topics related to digital transformation.

\section{Strategy}

Sharing a common digital vision is comprehended as an important factor for the successful outcome of digital transformation endeavours in our cases. Still, every company develops its strategy according to its own needs and the stage of its digital transformation process. This diversity in defining a digital transformation strategy was also noticed in research on three companies by Hess and colleagues (2016). In Manufact, the corporate strategy incorporates a digital vision. On the other hand, Teleop and Insurer enacted their strategies as separate strategic documents carefully aligned with corporate strategic vision. However, according to Teleop, the company no longer relies on the strategy very much nowadays. This is due to entering a more mature stage of organizational digital transformation, to cite the Teleop respondents - the "organization for the digital era", which represents the company once a digital culture is incorporated into its organizational structures. Regardless of the differences in strategic approaches, two common notions are evident: i) defining a Chief Digital Officer (CDO) role in charge of digital transformation projects and efforts and ii) strong support of the board. Even though the official CDO role has not been established yet in Manufact, the company's CEO plays a partial role of a CDO by strongly reinforcing digital projects. Other authors also streses the significance of supporting the capacity and influence of a $\mathrm{CDO}$ in a process of digital transformation (Horlacher \& Hess, 2016; Singh \& Hess, 2017). Nevertheless, even with the top-level management vision and support, a battle for gaining resources (both human and financial) among competitive organizational projects remains, which holds repercussions for talent development, as discussed in the next subsection.

\section{People}

In order to develop a digital culture and also gain competitive advantage, organizations employ measures for acquiring employees with digital skills and encouraging a culture of knowledge-sharing in the workplace. For instance, Insurer recruited a new CDO from the telecommunications industry, which is acknowledged as a pioneering sector in digital transformation (e.g., Westerman et al., 2012; Kane et al., 2015). With years of relevant experience, Insurer's new CDO is expected to assist with the digital transformation process after the initial enactment of the digital strategy. Other employees with digital skills are also specifically recruited. These employees can then collaborate on digital projects, inside their original teams or outside them, depending on the sort of project or matrix organizational structure in the company.

They also advocate for a culture of knowledge-sharing and help their peers selflessly. Having in mind benefits for the company and work outcome, they do it without fear of someone else taking credit for their input. In the experience of all of the case companies, these qualities seem to be inherent to the younger demographic of employees. In Manufact, younger employees adjust faster to novelties and, hence, provide internal education and transfer their knowledge to the rest of the company, especially after returning from formal education. With such a practice, a number of employees that can participate in digital solutions development increases, thereby leveraging limited human resources in times of increased project activity.

\section{Organization}

A digital transformation unit cannot operate alone, nor can a digital project be run separately from the rest of the company. Hence, digital transformation requires the inclusion of staff from other departments besides the digital transformation unit. This phenomenon was previously noticed by Teleop, who had for this reason advisedly dissolved their digital transformation unit but retained the function of a CDO. Members of the digital transformation are now intentionally distributed over the company to foster a digital spirit and assist internally in digital projects. In the words of Teleops' current CDO: "We did this allocation specifically with the aim 


\section{Mastering the Digital Transformation Process: Business Practices and \\ Lessons Learned Lucija Ivančić, Vesna Bosilj Vukšić, and Mario Spremić}

Table 2. Organizational resources and activities in the digital transformation process (continued on next page)

\begin{tabular}{|c|c|c|c|c|}
\hline \multirow[t]{5}{*}{ Strategy } & Digital strategy has been enacted. & $\checkmark$ & & $\checkmark$ \\
\hline & $\begin{array}{l}\text { Digital strategy is aligned with corporate } \\
\text { strategic vision. }\end{array}$ & $\checkmark$ & $\checkmark$ & $\checkmark$ \\
\hline & $\begin{array}{l}\text { Subsequent transformation phases to help } \\
\text { operationalize activities are designed. }\end{array}$ & $\checkmark$ & & $\checkmark$ \\
\hline & $\begin{array}{l}\text { Board of directors supports digital } \\
\text { transformation }\end{array}$ & $\checkmark$ & $\checkmark$ & $\checkmark$ \\
\hline & $\begin{array}{l}\text { Digital transformation includes business } \\
\text { process enhancement, standardization, } \\
\text { and IT integration that supports digitized } \\
\text { solutions. }\end{array}$ & $\checkmark$ & $\checkmark$ & $\checkmark$ \\
\hline \multirow[t]{2}{*}{ People } & $\begin{array}{l}\text { Digital skills are developed through } \\
\text { constant training and education (internal } \\
\text { and external; formal and informal). }\end{array}$ & $\checkmark$ & $\checkmark$ & $\checkmark$ \\
\hline & $\begin{array}{l}\text { Talent development HR process is in } \\
\text { place. }\end{array}$ & $\checkmark$ & & $\checkmark$ \\
\hline \multirow{4}{*}{ Organization } & $\begin{array}{l}\text { Digital transformation unit or } \\
\text { "evangelists" report directly to higher } \\
\text { management. }\end{array}$ & $\checkmark$ & $\checkmark$ & $\checkmark$ \\
\hline & $\begin{array}{l}\text { Digital projects are run through the } \\
\text { project organizational structure. }\end{array}$ & $\checkmark$ & $\checkmark$ & $\checkmark$ \\
\hline & $\begin{array}{l}\text { Organizational measures include digitally } \\
\text { related key performance indicators (KPIs). }\end{array}$ & $\checkmark$ & $\checkmark$ & $\checkmark$ \\
\hline & $\begin{array}{l}\text { Common management practices from the } \\
\text { fields of organization management and } \\
\text { operations management are utilized. }\end{array}$ & $\checkmark$ & $\checkmark$ & $\checkmark$ \\
\hline
\end{tabular}




\section{Mastering the Digital Transformation Process: Business Practices and \\ Lessons Learned Lucija Ivančić, Vesna Bosilj Vukšić, and Mario Spremić}

Table 2. (continued) Organizational resources and activities in the digital transformation process

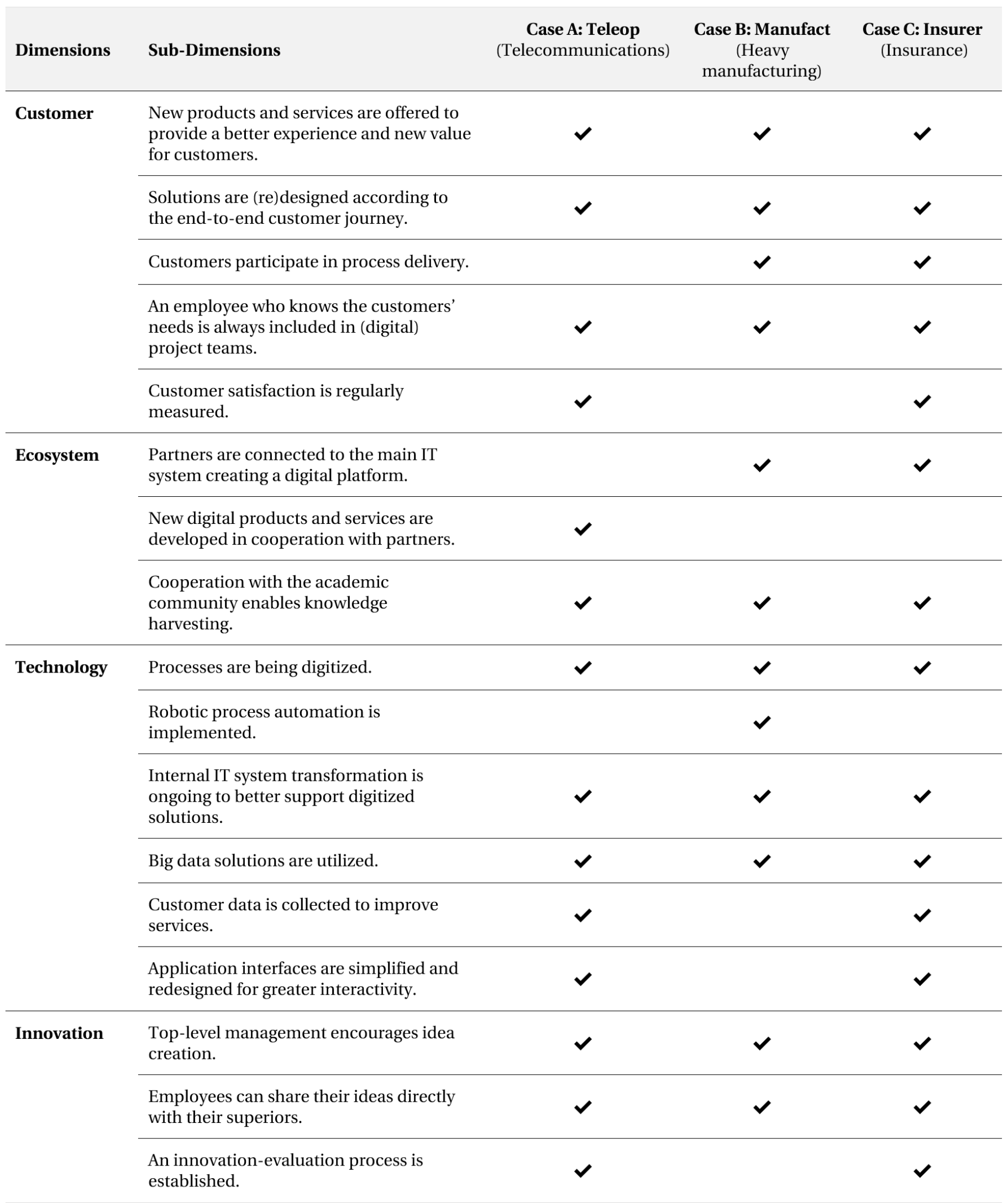




\section{Mastering the Digital Transformation Process: Business Practices and Lessons Learned Lucija Ivančić, Vesna Bosilj Vukšić, and Mario Spremić}

that they [the members of the digital transformation unit] cultivate digital transformation, but this time from another direction, from the business units themselves or from IT."

The adoption of new technologies for: i) utilization purposes (e.g., handling robotic automation in Manufact or digitized processes and points of sales in Insurer) or ii) new solutions development (e.g., new infrastructure for services based on Big Data in Teleop or software technologies for robotic reprogramming in Manufact) requires constant training. Alongside with internal training, opportunities for external training are also offered to employees. These can include earning standardized certificates or somewhat less formal education such as partnering with Gartner for the provision of individual on-request consulting services, which is the case in Teleop. Also, in Teleop, a specific focus is put on agile education, such as acquiring Scrum certificates with the aim of creating an Agile project organization, which is reasonable since, according to Recker and colleagues (2017), projects to implement information systems depend on a company's capacity for agility.

Coping with constant changes that come along with a process of digital transformation can be difficult. As remarked by one of the respondents from Insurer: "We implement changes pretty fast, and just to change something isn't enough. People are overwhelmed by them and find it hard to adapt. A certain fatigue could have been detected lately." To overcome this issue, Insurer has implemented a change management process. A similar experience was reported by Manufact. They came to the conclusion that a more personal approach would be more suitable for their company. Individual employee conversations are held to communicate changes, alongside with 360-degree feedback for open evaluation of coworkers, regardless of the hierarchy. Other practices and methods from the field of organization management and operations management are also utilized, including methodologies related process management such as Business Process Management and Lean Management. These methods support digital transformation in companies from an organizational perspective, such as human resources or operational excellence.

\section{Customer}

Quality of service provision is a more prominent consideration in Insurer and Teleop, which due to nature of their business, consider operational outcomes as a combination of customer journey design with technolo- gies implemented to speed-up end-to-end customer-related processes. The end-to-end customer journey is a key guide in designing digital solutions. In Insurer, it is also used as a decision-support tool for process changes. Products and services are (re)designed in order to provide better customer experience, advance service quality, and create new value for the customers, all while having in mind distinctive market characteristics and being guided by customer needs. For example, even though a social network and the online omnipresence of customer support is $24 / 7$ available to the Teleops' customers, their buyers in one market are more inclined to prefer personal contact, meaning they are more like to visit a physical customer centre. In that light, Teleop has revised its centres' opening hours. The decision-support system for altering the opening hours was enriched with information from software analyzing people density and movement data, collected from telecommunications mobile network. Analysis of network traffic data enabled the detection of busy periods and informed decisions about the centres' optimal locations and opening hours.

Due to the manufacturing economic activity of Manufact, which by nature has a limited number of customer touch/engagement points, the end-to-end journey is achieved through an online ordering system and adapting the process outcomes and key performance indicators (KPIs) to customer needs. Besides reducing the product errors, automation provided Manufact with well-needed speed in delivering project deadlines with highly time-sensitive customers. Due to this competitive advantage, Manufact closes deals by virtue of being able to deliver the product faster than the other global competitors. Another customer-related aspect of digital transformation is greater involvement of customers in business processes. In Manufact, customers start sessions in the production system through an online sales portal, whereas the clients in Insurer are entitled and encouraged to use digital channels to make damage claims on their insurance policies - a process which once required the agent to go out on a field assessment.

\section{Ecosystem}

The highest goal of digital transformation in our cases is greater inclusion of customers in company processes, often through the digital platform, which creates a business atmosphere where customers are perceived as partners. On one hand, given that the main business activity of Teleop is the provision of core telecommunication infrastructure and services, partnering in network projects for the Internet of Things (IoT) creates 


\section{Mastering the Digital Transformation Process: Business Practices and Lessons Learned Lucija Ivančić, Vesna Bosilj Vukšić, and Mario Spremić}

new market and revenue opportunities for the company and other parties willing to connect to the network. On the other hand, sharing of the available mobile network traffic data raises the overall efficiency of partners involved in the ecosystem. Indeed, the greater need for knowledge, which is driven by current digitization, fosters collaboration with partners, including business-to-business (B2B) customers, public and government organizations, or even unknown actors in a process of value co-creation (Brust et al., 2017; Hossain \& Heidemann Lassen, 2017; Pellikka \& Ali-Vehmas, 2016). Also observable from our cases is a close connection with the academic community with the aim of soliciting knowledge, innovations, and human resources. The most eminent example of academic partnering is in the Silicon Valley where a circle of IT firms and firms from other sector, startups, and the academic community evolves for new value creation (Kane et al., 2017).

\section{Technology}

Incumbent digital technologies can be observed according to the strength of affiliation with the traditional corporate IT. Hence, we can classify digital technologies as primary (e.g., mobile, social, cloud, Big Data, and IoT and secondary or emerging (e.g., 3D printing, wearables, virtual and augmented reality, artificial intelligence, drones and robotics, and deep learning algorithms (Spremić, 2017). As such, organizations have the option to choose from a pool of abundant modern technologies, depending on the digitization areas they are focused on. As it turns out, companies do not excel in all implementation areas (Westerman et al., 2012), and as observable from our cases, neither do they have the urge to do so. Having its niche in manufacturing industry, Manufact focused its implementations on the production line, introducing robotic automation. Robots can observe and act in response to the observed environment, thereby minimizing the need for human involvement and reducing product errors. Insurers' digitization efforts are directed towards customer-oriented process digitization. Tablet PCs are used remotely, providing agents with access to quality information and allowing them to complete tasks even at a distance. Providing instant service in the customers' locations, mobile agents empower agility and better customer satisfaction with services.

As evident from Table 1, all three of the companies utilize Big Data and related technologies to gain additional insights and generate new value out of data. Some of the companies have used the existing data, which has previously not been exploited, whereas other ones noticed the opportunity to collect new data to infer conclusions or offer new services. Manufact introduced production-line cameras and an image-recognition algorithm for quality control and quality assurance, whereas Insurer uses open public geographical data in combination with drones in the process of environmental damage assessment. Teleop, on the other hand, used existing network data (anonymized and generalized) to provide diverse stakeholders with information about the network traffic. Such information enables the bank to optimize the locations of automated teller machine, for instance. Or, it can help tourism offices decide where to place tourist guides and multi-language signs.

Furthermore, alongside the adoption of digital technologies, our companies stressed the need for a quality enterprise resource planning (ERP) system in the background and undertaken efforts to standardize business processes. Process digitization calls for revision and standardization of the process, in terms of workflow, but also the terminology, especially in service industries, which, as also seen in the financial sector, have a diverse portfolio of products and many communication and sales channels. Likewise, Insurer put efforts into employee education and the harmonization of process nomenclature so that a certain product would be offered under the right name to the customer and therefore would launch the correct process instance in the digital platform. In addition to that, an efficient ERP system in the background joins utilized digital technologies into one IT system and empowers information flow.

\section{Innovation}

Innovation generation is strongly encouraged by the management of our case companies. Ideas are transferred to the supervisors through diverse channels, although in Manufact it is not uncommon to approach the general director directly with ideas, thereby bypassing the chain of command. By the narrative of Manufacts' CEO: "People say that they came because they have a great idea and worry it will be lost in the hierarchy. So, they approach me, and I support that kind of behaviour." They also explained that this practice is sufficient for handling incoming innovation ideas, for the time being. Interestingly, these initiatives regularly come from younger employees. Hence, a special effort is put into employing engineers with innovative, curious, and proactive mindsets. Teleop has adopted a somewhat more formal approach for idea evaluation by 


\section{Mastering the Digital Transformation Process: Business Practices and Lessons Learned Lucija Ivančić, Vesna Bosilj Vukšić, and Mario Spremić}

constituting a special board that is convened monthly in so called "idea pitch" sessions to assess large projects proposed by employees. However, in the experience of Teleop, and other cases around the globe (Kane et al., 2016), innovations do not have to be game-changing. They can be modest, such as Teleop starting to use Word documents along with digital signatures to digitize the administrative process of exchanging student contracts between three parties.

At Insurer, the top management team's openness to new ideas has resulted in a great and ever-increasing number of ideas that became hard to administer. They try to counteract this issue with an Innovation Committee along with an idea-management portal on the Intranet for employees to apply their ideas to the evaluation process. Insurers' CDO explains the reason behind this business move: "The volume of these ideas is enormous! Besides that, after idea submission, our employees expect first of all to get feedback, and afterwards, they expect someone to be dealing with the idea and [to know] who would, in the end, come with an implementation proposal addressing the underlying issue. Above all that, in order to keep employees content, we have to be able to repeat the process and make it sustainable. In other words, we need to have a team constantly employed on these activities."

Another common innovation management activity in companies is an annual "innovation competition" (Kane et al., 2018; Westerman et al., 2012). According to Westerman and colleagues (2012), competitions train employees to think of new ideas and help them identify gaps in business that could be innovated. Our case companies regularly finance these kinds of meetings, which also include external participants, or they take part in student case studies and business or technological idea competitions. Regardless of the adopted approach, evident from our research is that systematic efforts to encourage idea generation and maintenance should be undertaken in order to convey ideas to valuegenerating innovations and benefit from the company's innovation potential.

\section{Discussion and Lessons Learned}

The seven main dimensions of the digital transformation identified from our research are strategy, people, organization, customer, ecosystem, technology, and innovation (Table 2). The identification of these dimensions supports related works arguing that digital transformation is much more than simply employing digital technologies (Kane et al., 2015; Kohnke, 2017).
The strategy dimension encompasses the enactment of digital strategy and other means for ensuring proper governance. Although some authors emphasize the importance of digital transformation strategy (Hess et al., 2016), we found that digital ambition is a more important factor for successful transformation, since the ultimate goal is to have "digital" institutionalized as an ordinary company setup. Nevertheless, for starters, digital strategy enactment can be a good start to a digital transformation process. The innovation dimension encompasses the means and resources that enable innovation generation and management, and it is connected with sub-dimensions related to organization and people dimensions, since innovation capacity is determined by human capital and can be developed through workshops and other educational methods. Other supporting evidence of "people" as an important category in digital transformation setting can be found in the literature (Kane et al., 2015; Kane et al., 2016). The case companies we investigated digitize processes and develop new digital services and solutions, which could not be possible without an efficient operational system in the background to ensure information flow between different digital solutions and applications. Our findings regarding the technology dimension are in good agreement with the works on the importance of the role of business-management systems in digital transformation (Asprion et al., 2018; Sebastian et al., 2017). For instance, Sebastian and co-authors (2017) argue that there are two technology assets that serve as enablers for digital transformation: operational backbone and digital services platform. Managing changes that come with digital transformation can be overwhelming, and all of our companies agree that employing a change-management process is perhaps more important than ever in this digital age. Employees get used to specific work patterns, and changing their habits without communicating and implementing such changes properly can undermine digital efforts. Change management, HR conversations with employees, and education help employees adapt to change and contribute to a digital culture in the company.

Through the process of digitally transforming, companies discover the most suitable means for themselves as the "learn by doing". Likewise, there are differences in stages of digital transformation among companies that can be explained by digital transformation start period, as shown in Table 3 . Whereas Table 2 presents resources and practices in digital transformation, Table 3 envelops information that provides an overview of the state of digital transformation process by each case. Table 3 also points out each company's most important 


\section{Mastering the Digital Transformation Process: Business Practices and \\ Lessons Learned Lucija Ivančić, Vesna Bosilj Vukšić, and Mario Spremić}

Table 3. Process characteristics and lessons learned in digital transformation

\begin{tabular}{|c|c|c|c|}
\hline & $\begin{array}{l}\text { Case A: Teleop } \\
\text { (Telecommunications) }\end{array}$ & $\begin{array}{c}\text { Case B: Manufact } \\
\text { (Heavy manufacturing) }\end{array}$ & $\begin{array}{l}\text { Case C: Insurer } \\
\text { (Insurance) }\end{array}$ \\
\hline Start of digital transformation process & 6 years ago & 1.5 years ago & 2 years ago \\
\hline $\begin{array}{l}\text { Internally defined phase of digital } \\
\text { transformation process }\end{array}$ & Phase 3 & Phase 1 & Phase 2 \\
\hline $\begin{array}{l}\text { Description of internally defined phase of } \\
\text { digital transformation process }\end{array}$ & $\begin{array}{l}\text { Digital culture } \\
\text { developed after three } \\
\text { strategies; new business } \\
\text { models adopted }\end{array}$ & $\begin{array}{l}\text { Still in the beginning; no } \\
\text { formal strategy defined } \\
\text { but digital projects in } \\
\text { place }\end{array}$ & $\begin{array}{l}\text { Several projects } \\
\text { finished; a second } \\
\text { strategy is on its way }\end{array}$ \\
\hline Main goal of digital transformation & $\begin{array}{l}\text { Find new business } \\
\text { models and } \\
\text { monetization methods }\end{array}$ & $\begin{array}{l}\text { Create a completely } \\
\text { automated production } \\
\text { process }\end{array}$ & $\begin{array}{l}\text { Offer new services and } \\
\text { keep or enlarge } \\
\text { customer portfolio }\end{array}$ \\
\hline $\begin{array}{l}\text { Operational backbone characteristics } \\
\text { Adapted from Sebastian et al. (2017) }\end{array}$ & $\begin{array}{l}\text { Standardized key } \\
\text { business processes and } \\
\text { organizational } \\
\text { management system } \\
\text { (home grown) }\end{array}$ & $\begin{array}{l}\text { Standardized key } \\
\text { business processes and } \\
\text { organizational } \\
\text { management system } \\
\text { (home grown) }\end{array}$ & $\begin{array}{l}\text { Standardized key } \\
\text { business processes and } \\
\text { centralized customer } \\
\text { database (home grown) }\end{array}$ \\
\hline $\begin{array}{l}\text { Digital services platform characteristics } \\
\text { Adapted from Sebastian et al. (2017) }\end{array}$ & $\begin{array}{l}\text { Personalized, flexible } \\
\text { customer experience } \\
\text { within a topic area (in } \\
\text { progress) }\end{array}$ & $\begin{array}{l}\text { Aggregation and analysis } \\
\text { of different data from } \\
\text { sensors, devices, other } \\
\text { sources }\end{array}$ & $\begin{array}{l}\text { Continually adjusted, } \\
\text { personalized customer } \\
\text { experience with } \\
\text { analytics and } \\
\text { behavioural economics } \\
\text { (in progress) }\end{array}$ \\
\hline $\begin{array}{l}\text { Selected digital transformation success } \\
\text { indicator }\end{array}$ & $\begin{array}{l}\text { Launched customer } \\
\text { application for } \\
\text { integrative service } \\
\text { management }\end{array}$ & $\begin{array}{l}20 \% \text { export products } \\
\text { segment yearly growth }\end{array}$ & $\begin{array}{l}23 \% \text { premium online } \\
\text { insurance policy growth } \\
\text { in } 2018\end{array}$ \\
\hline $\begin{array}{l}\text { Lessons learned and recommendations } \\
\text { As described in digital transformation } \\
\text { framing (Table 2) }\end{array}$ & $\begin{array}{l}\text { Ask the users if solution } \\
\text { makes sense; maximize } \\
\text { available data } \\
\text { monetization potential; } \\
\text { CDO is a bridge and a } \\
\text { separator }\end{array}$ & $\begin{array}{l}\text { Ally with universities } \\
\text { and hire young people } \\
\text { and those with proactive } \\
\text { mindsets }\end{array}$ & $\begin{array}{l}\text { Maintain or develop } \\
\text { high service quality and } \\
\text { employ change } \\
\text { management }\end{array}$ \\
\hline $\begin{array}{l}\text { Priority dimension } \\
\text { Following digital transformation framing } \\
\text { (Table 2) and Lessons learned and } \\
\text { recommendations (in previous row) }\end{array}$ & $\begin{array}{l}\text { - Customer } \\
\text { - Technology } \\
\text { - Strategy }\end{array}$ & $\begin{array}{l}\text { - Ecosystem } \\
\text { - People }\end{array}$ & $\begin{array}{l}\text { - Technology } \\
\text { - Organization }\end{array}$ \\
\hline
\end{tabular}




\section{Mastering the Digital Transformation Process: Business Practices and Lessons Learned Lucija Ivančić, Vesna Bosilj Vukšić, and Mario Spremić}

lessons learned. Although companies address all of the dimensions in the process of digital transformation, linking these lessons with digital transformation framing from Table 2 unfolds some priority dimensions.

Additionally, we asked our companies to select one KPI or successful project that they are mostly proud of and that was facilitated due to activities of digital transformation. The selected success indicators are in good agreement with the main goals of digital transformation and can be correlated with industry and niche particularities.

Teleop has passed through several phases of digital transformation. Currently, its digital strategy does not coexist as a separate document; rather, it is a coherent part of other strategies and a way of doing business, with emphasis placed on customer orientation. In Teleop, they consider their company to have achieved a digital organizational culture. Since telecommunication companies are in a good position of having access to geolocation, customer, and other population data, a smart reflection would be to try to finding them a new, additional purpose. There are three recommendations emerging from the Teleop case. First, always ask the users, whether those are internal users (i.e., employees) or external users (i.e., customers) if the digitized process or solution makes sense - they are the company's best consultants. Second, companies should consider maximizing the available potential for data-monetization. Finally, make most out of the CDO role. Business units know the customer, and IT units should not be burdened by endless business meetings and discussions. Rather, they should have enough time for technology implementation set out by the CDO. The CDO is both a bridge and a separator between business units and IT that ensures smooth project development and implementation.

In 2018 , Insurer reported $23 \%$ growth in premiums for online insurance policies, which is consistent with efforts to enlarge its customer portfolio while providing a high-quality service standard. Growth was facilitated by related operational steps and enablers in the digital transformation project: creating a digital insurance policy, simplifying the buying procedures, increasing the number of maximum periods for paying in installments from 10 to 12 , removing 3D security in credit card payments with accompanying risk assessment, analyzing daily consumer visits, and conducting behavioural analytics in the customer journey coordinated with digital marketing. As far as Insurer is concerned, a key to successful digital transformation would be to en- sure continuously high service quality for external customers (i.e., buyers) and employ change management so that internal customers (i.e., employees) are satisfied and efficient.

Being an export-oriented manufacturing company, Manufact seeks to create a completely automated production process including integration at the level of supply chain integration with partners. Although in the beginnings of formal digital transformation, Manufact already benefits from the digitization and innovation capacity of their employees. They are experiencing yearly growth of $20 \%$ in the export products segment. Robotic automation that uses sensors and Big Data in the production lines has enabled greater product quality in comparison to competitors, greater efficiency, and greater production capacity. Big foreign buyers considered these features as indicators of security and trust because they show that the company is ready to tackle the current market challenges (e.g., short timelines from order to delivery) that, in the end, lead to increased exports. According to Manufact, the main lessons learned in digital transformation relate to innovation capacity and generation: companies should not forget to ally with universities, and they should employ the best engineers that are willing to make a difference for the company.

\section{Conclusion}

Organizations struggle to employ effective combinations of best practices and available resources to make the most out of digital transformation, and the topic is still developing in academia. We tried to address this gap by performing a qualitative holistic investigation on digital transformation in three companies (Research Objective 1). Besides technologies adoption, we discovered that important co-factors of digital transformation are: i) the overall organizational setup supporting a digital culture and related changes ii) and operational process excellence with efficient integral information systems in the background. Special consideration in digital transformation needs to be made regarding change management, innovation management, and talent development. In the end, a digital mindset and digital skills have the potential of being an essential mediating capability in determining the success of digital transformation endeavours.

Inferring from the cross-sectional first-hand insights of our research, this article provided a systematic analysis of digital transformation in companies through univer- 


\section{Mastering the Digital Transformation Process: Business Practices and Lessons Learned Lucija Ivančić, Vesna Bosilj Vukšić, and Mario Spremić}

sal digital transformation resources and practices that are presented in a form of digital transformation dimensions and sub-dimensions (Research Objective 2). Taken together, the case companies addressed all of the identified dimensions, but we showed that certain dimensions can be prioritized depending on the main goals of digital transformation. In addition, particular focal areas, activities, and lessons learned related to certain company and sector are explained in the narratives.

Although this research contributes to the body of knowledge on digital transformation, the limitations of qualitative research need to be considered, such as the limited number of companies that originated from the same country. Nevertheless, we tried to counteract this limitation by selecting a diversified cross-sectional portfolio of distinguished companies, and hence, we believe that it is valid to generalize the findings. Future research attempts could evaluate our postulates in additional case studies or through a quantitative survey design.

We believe that a holistic investigation of the topic enriched with first-hand qualitative data provides many possibilities for further dissemination of the presented findings. The synthesis of our findings in the form of digital transformation framing with (sub)dimensions can be further utilized in digital transformation models and to construct hypotheses. Moreover, specific framing components reveal research topics that can be more thoroughly investigated in future studies.

Practitioners can benefit from business-related revelations presented in this article. Digital transformation framing alongside the recommendations from our case companies can be used to guide strategy. We encourage them to use our digital transformation framing and best practice examples to establish a well-defined digital transformation setting. As far as our own future research on the topic is concerned, we plan to continue investigating the digital transformation process in organizations and its underlying aspects in order to contribute to an ontology, as well as to provide the practitioner community with insights to guide the hands-on operation of their businesses.

\section{Acknowledgments}

This work has been partly supported by the University of Zagreb under the project Digital Transformation of Croatian Companies and partly by the Croatian Science Foundation under the project PROSPER - Process and Business Intelligence for Business Performance (IP2014-09-3729).

\section{About the Authors}

Lucija Ivančić is a Teaching and Research Assistant in Business Computing, Business Process Management, and Data Management, and a $\mathrm{PhD}$ candidate in the Department of Informatics of the Faculty of Economics and Business at the University of Zagreb, Croatia. Her current research interests lie in business process modelling and management, IT management, data management, and digital transformation, and at the intersection of these fields. She received two Dean's awards for previous papers on discreteevent simulation modelling and information systems auditing.

Vesna Bosilj Vukšić is a Professor of Business Process Management and Business Computing in the Department of Informatics of the Faculty of Economics and Business, at the University of Zagreb, Croatia. Her current research interests are in modelling and the management of business processes, information systems development, and digital transformation. Vesna has a teaching experience in undergraduate and postgraduate courses. She participates actively in research within the framework of the Ministry of Science and Technology's scientific projects, and is a member of international scientific research projects. She is a member of editorial boards and a reviewer of international scientific journals.

Mario Spremić is a Professor of ICT Governance and Digital Business in the Department of Informatics of the Faculty of Economics and Business at the University of Zagreb, Croatia. His current research interests are in digital transformation, digital technologies, ICT governance, cybersecurity, and IT auditing. Mario is teaching on these topics at the undergraduate and postgraduate levels, including some international engagements including as a guest lecturer at Imperial College London. He is a member of editorial boards and a reviewer of international scientific journals. 


\section{Mastering the Digital Transformation Process: Business Practices and \\ Lessons Learned Lucija Ivančić, Vesna Bosilj Vukšić, and Mario Spremić}

\section{References}

Asprion, P. M., Schneider, B., \& Grimberg, F. 2018. ERP Systems Towards Digital Transformation. In R. Dornberger (Ed.), Business Information Systems and Technology 4.0. Studies in Systems, Decision and Control, 141: 15-29. Cham, Switzerland: Springer. https://doi.org/10.1007/978-3-319-74322-6_2

Benbasat, I., Goldstein, D. K., \& Mead, M. 1987. Strategy in Studies of Information Systems. MIS Quarterly, 11(3): 369-386. https://doi.org/10.2307/248684

Berman, S. J. 2012. Digital Transformation: Opportunities to Create New Business Models. Strategy \& Leadership, 40(2): 16-24. https://doi.org/10.1108/10878571211209314

Bosilj Vukšić, V., Ivančić, L., \& Suša Vugec, D. 2018. A Preliminary Literature Review of Digital Transformation Case Studies. In Proceedings of the 20th International Conference on Managing Information Technology (ICMIT 2018): 737-742. Rome, September 17-18, 2018.

Brust, L., Antons, D., Breidbach, C. F., \& Salge, T. O. 2017. ServiceDominant Logic and Information Systems Research: A Review and Analysis Using Topic Modeling. In Proceedings of the International Conference on Information Systems. Association for Information Systems.

Buh, B., Kovačič, A., \& Indihar Štemberger, M. 2015. Critical Success Factors for Different Stages of Business Process Management Adoption - A Case Study. Economic Research-Ekonomska Istraživanja, 28(1): 243-258.

https://doi.org/10.1080/1331677X.2015.1041776

Gill, M., \& Van Boskirk, S. 2016. The Digital Maturity Model 4.0. Cambridge, MA: Forrester Research.

Henriette, E., Feki, M., \& Boughzala, I. 2015. The Shape of Digital Transformation: A Systematic Literature Review. Paper presented at the Ninth Mediterranean Conference on Information Systems (MCIS) 2015 Proceedings. Samos, Greece.

Hess, T., Matt, C., Benlian, A., \& Wiesböck, F. 2016. Options for Formulating a Digital Transformation Strategy. MIS Quarterly Executive, 15(2): 123-139. https://doi.org/10.1108/10878571211209314

Horlacher, A., \& Hess, T. 2016. What Does a Chief Digital Officer Do? Managerial Tasks and Roles of a New C-level Position in the Context of Digital Transformation. In Proceedings of the 49th Hawaii International Conference on System Sciences (HICSS 2016): 5126-5135. Piscataway, NJ: IEEE. https://doi.org/10.1109/HICSS.2016.634

Hossain, M., \& Heidemann Lassen, A. 2017. Q\&A. How Do Digital Platforms for Ideas, Technologies, and Knowledge Transfer Act as Enablers for Digital Transformation? Technology Innovation Management Review, 7(9): 55-60. http://doi.org/10.22215/timreview/1106

Kane, G. C., Palmer, D., Phillips, A. N., Kiron, D., \& Buckley, N. 2016. Aligning the Organization for Its Digital Future. MIT Sloan Management Review and Deloitte University Press.

Kane, G. C., Palmer, D., Phillips, A. N., Kiron, D., \& Buckley, N. 2017. Achieving Digital Maturity. MIT Sloan Management Review and Deloitte University Press.
Kane, G. C., Palmer, D., Phillips, A. N., Kiron, D., \& Buckley, N. 2018. Coming of Age Digitally. MIT Sloan Management Review and Deloitte Insights.

Kane, G. C., Palmer, D., Phillips, A. N., Kiron, D., \& Buckley, N. 2015. Strategy, Not Technology, Drives Digital Transformation. MIT Sloan Management Review and Deloitte University Press.

Kohli, R., \& Johnson, S. 2011. Digital Transformation in Latecomer Industries: CIO and CEO Leadership Lessons from Encana Oil \& Gas (USA) Inc. MIS Quarterly Executive, 10(4): 141-156.

Kohnke, O. 2017. It's Not Just About Technology: The People Side of Digitization. In G. Oswald, M. Kleinemeier (Eds.), Shaping the Digital Enterprise: 69-91. Cham, Switzerland: Springer International Publishing.

https://doi.org/10.1007/978-3-319-40967-2_3

Lucas, H. C. J., Agarwal, R., Clemons, E. K., El Sawy, O. A., \& Weber, B. 2013. Impactful Research on Transformational Information Technology: An Opportunity to Inform New Audiences. MIS Quarterly, 37(2): 371-382. https://doi.org/10.25300/MISQ/2013/37.2.03

Matthews, B., \& Ross, L. 2010. Research Methods. A Practical Guide for the Social Sciences. Harlow, UK: Pearson Longman.

Myers, M. D. 1997. Qualitative Research in Information Systems. MIS Quarterly, 21(2): 241-242.

https://doi.org/10.2307/249422

Myers, M. D., \& Newman, M. 2007. The Qualitative Interview in IS Research: Examining the Craft. Information and Organization, 17(1): $2-26$ https://doi.org/10.1016/j.infoandorg.2006.11.001

Niehaves, B., Poeppelbuss, J., Plattfaut, R., \& Becker, J. 2014. BPM Capability Development - A Matter of Contingencies. Business Process Management Journal, 20(1): 90-106. https://doi.org/10.1108/BPMJ-07-2012-0068

Pellikka, J., \& Ali-Vehmas, T. 2016. Managing Innovation Ecosystems to Create and Capture Value in ICT Industries. Technology Innovation Management Review, 6(10): 17-24. https://doi.org/10.22215/timreview1024

Recker, J., Holten, R., Hummel, M., \& Rosenkranz, C. 2017. How Agile Practices Impact Customer Responsiveness and Development Success: A Field Study. Project Management Journal, 48(2): 99-121. https://doi.org/10.1177/875697281704800208

Sebastian, I. M., Ross, J. W., Beath, C., Mocker, M., Moloney, K. G., \& Fonstad, N. O. 2017. How Big Old Companies Navigate Digital Transformation. MIS Quarterly Executive, 16(3): 197-213.

Singh, A., \& Hess, T. 2017. How Chief Digital Officers Promote the Digital Transformation of their Companies. MIS Quarterly Executive, 16(1): 1-17.

Spremić, M. 2017. Governing Digital Technology - How Mature IT Governance Can Help in Digital Transformation? International Journal of Economics and Management Systems, 2: 214-223.

Voss, C., Tsikriktsis, N., \& Frohlich, M. 2002. Case Research in Operations Management. International Journal of Operations \& Production Management, 22(2): 195-219. https://doi.org/10.1108/01443570210414329 


\section{Mastering the Digital Transformation Process: Business Practices and \\ Lessons Learned Lucija Ivančić, Vesna Bosilj Vukšić, and Mario Spremić}

Vukšić, V. B., Bach, M. P., \& Popovič, A. 2013. Supporting Performance Management with Business Process Management and Business Intelligence: A Case Analysis of Integration and Orchestration. International Journal of Information Management, 33(4): 613-619. https://doi.org/10.1016/j.ijinfomgt.2013.03.008

Westerman, G., Calméjane, C., Bonnet, D., Ferraris, P., \& McAfee, A. 2011. Digital Transformation: A Road-Map for Billion-Dollar Organizations. Paris: Capgemini Consulting.

Westerman, G., Tannou, M., Bonnet, D., Ferraris, P., \& McAfee, A. 2012. The Digital Advantage: How Digital Leaders Outperform their Peers in Every Industry. MIT Center for Digital Business and Capgemini Consulting.

World Economic Forum. 2018. The Digital Enterprise. Moving from Experimentation to Transformation. Geneva: World Economic Forum.
Yin, R. K., Clarke, C., Cotner, B., \& Lee, R. 2006. Case Study Methods. In J. L. Green, G. Camilli, P. B. Elmore, A. S. K. Grace, \& E. Grace (Eds.), Handbook of Complementary Methods for Research in Education (3rd ed.). Abingdon, UK: Routledge. https://doi.org/10.4324/9780203874769.ch6

Zhu, K., Dong, S., Xu, S. X., \& Kraemer, K. L. 2006. Innovation Diffusion in Global Contexts: Determinants of Post-Adoption Digital Transformation of European Companies. European Journal of Information Systems, 15(6): 601-616. https://doi.org/10.1057/palgrave.ejis.3000650

\section{Appendix 1. Illustrative questions from the semi-structured interviews}

- What does digital transformation mean for you? How do you understand it?

- When (what) would (or will) mean that your company is "digitized"? Do you see this as a project(s) or as a permanent process? Would you agree with the claim that digitization is the use of digital technology for changing business models and processes and creating new business opportunities?

- In your opinion, how will digitization disrupt your industry?

- When did you start systematically / formally with digitization your company and what was its development?

- In which area do you implement digitization projects? To what extent? Are they focused on customer engagement or on the digitization of products/services?

- In which area are you planning to start projects in one year or in the next two to five years? To what extent? Are they focused on customer engagement or on the digitization of products/services?

- Do you have a digitization strategy in your company? Is the digitization strategy independent or is it included in the IT strategy / business strategy? In what relation is the digitization strategy with other company strategies? Is it aligned with other strategies?
- What are the roles of different $\mathrm{CxO}$ (CDO, CEO, COO, $\mathrm{CMO}, \mathrm{CIO}$ ) in formulating the digitization strategy?

- How (would) you measure the progress in your company in the field of digital transformation?

- Does digitization have a significant impact on your business models?

- Do you pursue the following goals through digitization: increasing efficiency, increasing innovation, improving business decision-making, significantly transforming business processes?

- What is the role of CIO (or highly ranked employee responsible for IT)? Work role? Where in the hierarchy of the organization is he/she positioned?

-What is the role of CDO (or highly ranked employee responsible for digitization)? Work role? Where in the hierarchy of the organization is he/she positioned?

- To what extent do you digitize customer engagement?

- Are external stakeholders also involved in digitization? How do you connect with external actors? What role do they have?

- Are your processes digitized (IT implementation)? Are you using ERP / CRP / SCM / PLM... solutions? What is the level of their integration over the processes? 


\section{Mastering the Digital Transformation Process: Business Practices and \\ Lessons Learned Lucija Ivančić, Vesna Bosilj Vukšić, and Mario Spremić}

- How do you ensure the connectivity and transparency of your processes? How do you provide crucial information in your company? In your opinion, is it always available on time? Is the information correct? Is there one version of the truth?

- To what extent do you digitize your products and services (digitized solutions)?

- Where do digitization initiatives come from? Who participates in digitization projects?

- What knowledge and skills are needed for participants digitizing projects?

- Do employees have adequate knowledge and skills? How do they obtain them? What knowledge and skills possess individual participants have (IT personnel, employees responsible for digitization)?

-What are the roles of individual stakeholders in digitization? Did the roles change? How? Do individual stakeholders cooperate with each other? How? How are they involved in defining, designing, and implementing digital transformation? How do you personally evaluate the cooperation between individual stakeholders?

- How do different stakeholders identify and co-create value in digitization? How are IT personnel included? Are they covering business or technical aspects (or both)?

- How is your company strengthening digital innovation capabilities? Developing the digital capabilities of existing employees; collaboration with contractors and consultants; cooperation with other organizations (e.g. partnerships and other forms of cooperation); recruiting employees with relevant knowledge in the field of digitization; recruiting leaders (managers) with relevant knowledge in the field of digitization; mergers and acquisitions?

- How do employees in the company accept digital transformation?

- Are employees keen on (support) the changes that are caused by digital transformation? Any differences between different groups? How do you encourage employees to adopt the changes caused by digital transformation?
Citation: Ivančić, L., Bosilj Vukšić,V., \& Spremić, M. 2019 Mastering the Digital Transformation Process: Business Practices and Lessons Learned. Technology Innovation Management Review, 9(2): 36-50.

http://doi.org/10.22215/timreview/1217

Keywords: digital transformation, digitization, digital business, digital transformation model, digital model, talent management, human capital, innovation management, change management, case study (cc) BY 


\section{Academic Affiliations and Funding Acknowledgements}
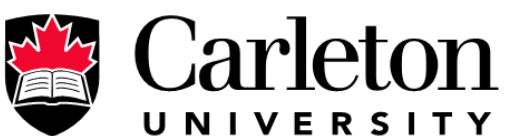

U N I V E R S I T Y

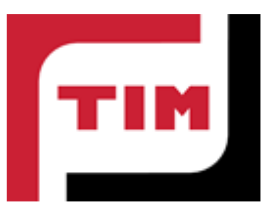

Technology Innovation Management (TIM; timprogram.ca) is an international master's level program at Carleton University in Ottawa, Canada. It leads to a Master of Applied Science (M.A.Sc.) degree, a Master of Engineering (M.Eng.) degree, or a Master of Entrepreneurship (M.Ent.) degree. The objective of this program is to train aspiring entrepreneurs on creating wealth at the early stages of company or opportunity lifecycles.

- The TIM Review is published in association with and receives partial funding from the TIM program. 